\title{
Preparation and Characterization of Holmium-Beta-Cyclodextrin Complex
}

\author{
Ana Rosa Rojas-Mena1, Hilario López-González¹, Alberto Rojas-Hernández² \\ ${ }^{1}$ Departamento de Química, Gerencia de Ciencias Básicas, Dirección de Investigación Científica, Instituto \\ Nacional de Investigaciones Nucleares, México, D. F., México \\ ²́rea de Química Analítica, Departamento de Química, Universidad Autónoma Metropolitana-Iztapalapa, \\ México, D. F., México \\ Email: Hilario.lopez@inin.gob.mx, suemi918@xanum.uam.mx
}

Received 29 January 2015; accepted 2 March 2015; published 6 March 2015

Copyright (C) 2015 by authors and Scientific Research Publishing Inc.

This work is licensed under the Creative Commons Attribution International License (CC BY).

http://creativecommons.org/licenses/by/4.0/

(c) (i) Open Access

\begin{abstract}
The purpose of this study was to prepare and characterize of holmium-beta-cyclodextrin complex (Ho- $\beta$-CD) in order to increase the solubility and stability of Holmium. To achieve this goal, Ho- $\beta$ CD complex was prepared by evaporation method of holmium and beta cyclodextrin solutions in a proportion (1:1) and (1:3), respectively. Infrared (IR) and Raman spectroscopy, X-Ray Diffraction were performed to identify the complex. Morphology of the Ho, $\beta$-CD, and Ho- $\beta$-CD were studied using Scanning Electron Microscopy (SEM).
\end{abstract}

\section{Keywords}

Holmium, $\beta$-Cyclodextrin, Inclusion Complex Ho- $\beta$-CD

\section{Introduction}

Lanthanide series may be divided into two groups: the light lanthanide elements (La, Ce, Pr, Nd, Pm, Sm, Eu) and the heavy rare elements (Gd, Tb, Dy, Ho, Er Tm Yb, Lu) [1]. Lanthanides are elements in which the forbitals are partly or completely filled, while the outermost $p$ and d orbitals are empty. Since the f orbitals do not have as much effect on the chemical properties as the p, and $d$, they are chemically very similar. The chemical characteristics of the lanthanides area dominated by their +3 oxidation state [1] [2].

Recently, in the pharmaceutical industry has appeared on the some novel metal drugs containing lanthanide cations with potential pharmacological applications essentially based on its similarity to calcium. The lanthanides for their size and electronic structure have some unique characteristics that make them suitable for certain therapeutic purposes and as diagnostic [3]. 
Among the radionuclide used for cancer therapy, ${ }^{131} \mathrm{I},{ }^{90} \mathrm{Y},{ }^{188} \mathrm{Re},{ }^{166} \mathrm{Ho}$, or ${ }^{153} \mathrm{Sm}$ are applied for the treatment of a multitude of malignant disorders; they have been used for cancer therapy, palliation of bone pain arising from secondary metastases, radio-synovectomy or intravascular radiation therapy [4].

${ }^{166} \mathrm{Ho}$ is used in nuclear medicine for the therapy of arthritis by radiation synovectomy for bone marrow ablation, and in the study of immunospecific radiopharmaceuticals, among others [5]-[7].

Several lanthanide complexes formed with acyclic and cyclic ligands have been prepared and evaluated for radiopharmaceuticals applications [8]. In order to get information, it is also important to prepare holmium complexes anchored by cyclodextrins.

Cyclodextrins (CDs) are cyclic oligosaccharides $(\alpha-1,4)$-linked of $\alpha$-D-glucopyranose containing a relatively hydrophobic central cavity and hydrophilic outer surface. The most common cyclodextrins are $\alpha$-cyclodextrin, $\beta$-cyclodextrin, and $\gamma$-cyclodextrin which contain 6, 7 and 8 glucopyranose units respectively. The melting point of $\alpha, \beta$ and $\gamma$-cyclodextrin are between $240^{\circ} \mathrm{C}$ and $265^{\circ} \mathrm{C}$ consistent with their stable crystal lattice structure [9]-[12]. The complexes formed by the CDs may favorably alter stability (volatile materials), solubility and bioavailability of encapsulated compound. Despite its high solubility in water, the internal cavity of cyclodextrins is non-polar and these compounds are capable of guest host complexes by inclusion of hydrophobic molecules [13].

Cyclodextrins are widely used in various fields of pharmaceutical industry such as drug delivery, stabilization of drugs, additives in the biotechnology and analytical methods etc. Cyclodextrins increase the water solubility of poorly soluble drugs and improve their bioavailability. Light thermal and oxidative stability of actives can be improved through the formation of cyclodextrin complexes [9]-[13].

In particular, the $\beta$-cyclodextrin, have a limited aqueous solubility (has the highest solubility of the CDs), and their complex formation with lipophilic drugs, and other compounds with limited aqueous solubility, frequently gives rise it [9]. That is why, $\beta$-CD to be employed in this research.

In this context, both holmium and beta cyclodextrin hold a distinctive place for all uses and applications that have been mentioned, consequently, is important to prepare inclusion complex holmium-beta-cyclodextrin to improve these pharmaceutical applications mainly.

For these reason, the aim of the present research was to prepare and characterize the inclusion compound Holmium- $\beta$-cyclodextrin.

\section{Material and Method}

\subsection{Materials}

All the chemical compounds were grade analytical, used as obtained, and solutions were prepared with distilled water. $\beta$-cyclodextrin ( $\beta$-CD), with molecular formula of $\mathrm{C}_{42} \mathrm{H}_{70} \mathrm{O}_{35}$ and molecular weight of $1134.98 \mathrm{~g} / \mathrm{mol}$, and holmium nitrate pentahydrate $\left(\mathrm{Ho}\left(\mathrm{NO}_{3}\right)_{3} \cdot 5 \mathrm{H}_{2} \mathrm{O}\right)$ with molecular weight of $382.56 \mathrm{~g} / \mathrm{mol}$, both were obtained from Sigma-Aldrich Company, Inc. Ethylene dinitrilotetraacetic acid disodium salt dehydrates (EDTA) and Xylenol orange were obtained from Merck Company.

\subsection{Preparation of $\beta$-Cyclodextrin and Holmium Solutions}

$\beta$-cyclodextrin was dissolved in distilled water and stirred for 30 minutes by sonication with Cole Parmer Ultrasonic equipment 8891 (Illinois, USA). The concentration of this solution was $0.002 \mathrm{M}$.

On the other hand, Holmium Nitrate pentahydrate was dissolved in $10^{-3} \mathrm{M}$ hydrochloride acid. The concentration of holmium $\left(\mathrm{Ho}\left(\mathrm{NO}_{3}\right)_{3} \cdot 5 \mathrm{H}_{2} \mathrm{O}\right)$ in the standard solution was determined by titration with a $0.025 \mathrm{M}$ EDTA solution. Three drops of pyridine and 3 drops of xilenol orange were also added. The holmium concentration in the standard solution was $0.4 \mathrm{M}$.

\subsection{Preparation of the Holmium- $\beta$-Cyclodextrin Inclusion Complex}

The inclusion complex of holmium with $\beta$-cyclodextrin (further abbreviated as Ho- $\beta$-CD) was prepared as following: solution of $\beta$-cyclodextrin was mixed with standard solution of the holmium in the molar ratio 1:1 Ho: $\beta$ CD or 1:3 Ho:3 $\beta$-CD, and stirred for 30 minutes by sonication. The resulting solution was slowly evaporated to dryness on a grill heating (Plate-Stirrer, Corning PC-351). Ho- $\beta$-CD obtained was washed with water and dried 
in an oven LAB-LINE Instrument at $60^{\circ} \mathrm{C}$ for 2 hours.

The Ho- $\beta$-CD inclusion complex was examined by infrared spectroscopy, Raman spectroscopy, X-Ray Diffraction, elemental analysis and scanning electron microscopy (SEM).

\subsection{Characterization of Holmium- $\beta$-Cyclodextrin Inclusion Complex}

\section{Scanning electron microscopy (SEM) and elemental analysis}

Surface morphology of Ho- $\beta$-CD was evaluated by scanning electron microscopy using a Philips XL30 FEGSEM. A voltage of 5 to $10 \mathrm{kV}$ was applied. Samples of $\beta$-cyclodextrin, Holmium Nitrate pentahydrate, and Ho- $\beta$-CD were mounted onto aluminium stubs and sputter-coated with a gold layer of about $10 \mathrm{~mm}$. These samples were analyzed by an energy dispersive X-ray spectrometer (EDX).

\subsection{Absorption Spectra}

A UV-Vis spectrophotometer (Perking Elmer UV-Vis lambda 10) with $1 \mathrm{~cm}$ quartz cells was used for all following spectroscopic studies. The absorption vs. wavelength profiles were obtained in the range of $200-700 \mathrm{~nm}$.

\subsection{Infrared Spectroscopy}

Infrared spectroscopies were recorded on a Nicolet Magna-IR 550 FT-IR spectrometer (Madison, Wiscosin, USA), in the range of $400-4000 \mathrm{~cm}^{-1}$. Samples of $\beta$-cyclodextrin, Holmium Nitrate pentahydrate, and Ho- $\beta$ $\mathrm{CD}$ were prepared by mixing with spectroscopy grade $\mathrm{KBr}$ grain. The $\mathrm{KBr}$ mixture was then pressed into a pellet. In addition to solid state IR experiments, samples were analyzed.

\subsection{X-Ray Diffraction Studies}

X-Ray Diffraction experiments were carried out by diffraction solid state X-ray equipment with powder diffractometer Siemens D-5000, with copper anode, $\lambda=1.5406 \AA$. The samples of the inclusion complex of Ho- $\beta$-CD (1:1), Ho- $\beta$-CD (1:3), $\left[\mathrm{Ho}\left(\mathrm{NO}_{3}\right)_{3} \cdot 5 \mathrm{H}_{2} \mathrm{O}\right]$, and $\beta$-cyclodextrin were placed in a specimen, it was introduced into a goniometer to which a beam made of $\mathrm{X}$-ray, obtaining a graph of intensity against diffraction angle with a sweep of $4^{\circ}$ to $70^{\circ} 2 \theta$. The results obtained were compared to cards patterns reported by the Joint Committee on Powder Diffraction Standards (JCPDS) to verify the presence of the material studied.

\subsection{Raman Spectroscopy}

Raman spectroscopy was performed on a Kaiser RXN spectrometer equipped with a $70 \mathrm{~mW} 785 \mathrm{~nm}$ diode laser for excitation, a holographic grating for dispersion and a peltier cooled Andor CCD camera for detection.

Raman spectroscopy was done using a Horiba-JobinYvonLabRamHR VIS high resolution confocal Raman microscope system with $633 \mathrm{~nm}$ laser.

\section{Results and Discussion}

\subsection{Scanning Electron Microscopy (SEM) and Elemental Analysis}

In Figure 1, a representative scanning electron microscopy (SEM) images are shown. We have found that the particles are heterogeneous, smooth, agglomerated surfaces and of different sizes in the ranging 10 to 30 micrometers in all the samples (Figures 1(a)-(d)).

In the case of Ho- $\beta$-CD can be seen is different from morphology reagents separately. It is obvious that Holmium- $\beta$-cyclodextrin Inclusion complex 1:1 and 1:3 are present Ho and $\beta$-CD according at differing rates. This suggested the Ho molecules are included in the $\beta$-CD inclusion complex.

EDS analysis in 10 different point of each sample to obtain an average of the elements constituting of each of these materials, shows the presence of several elements, the most abundant, holmium, nitrogen, carbon, oxygen, among others. The results are shown in Table 1.

The carbon in $\mathrm{Ho}\left(\mathrm{NO}_{3}\right)_{3} \cdot 5 \mathrm{H}_{2} \mathrm{O}$ is due at $\mathrm{CO}_{2}$ of the environmental. This compound is very hygroscopic. This effect was observed in the FTIR studies (absorption band $2362.72 \mathrm{~cm}^{-1}$ ), too. 

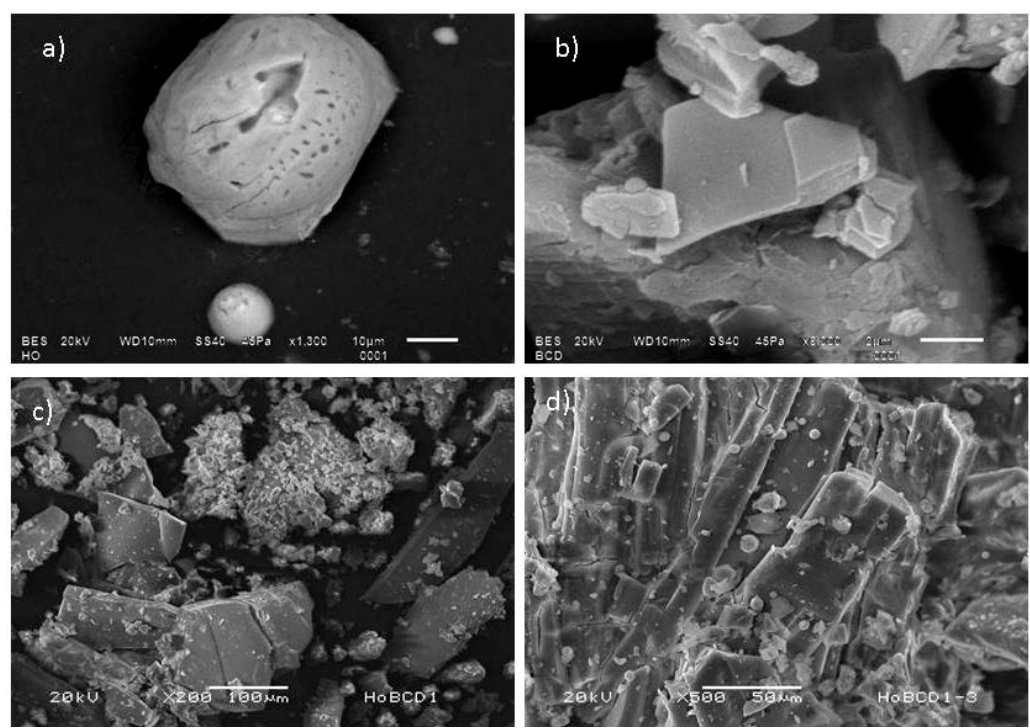

Figure 1. SEM images of (a) Holmium Nitrate Pentahydrate, (b) $\beta$-cyclodextrin, (c) Holmium- $\beta$-cyclodextrin Inclusion complex 1:1, (d) 1:3.

Table 1. Average values of the elements analysis found in the different samples.

\begin{tabular}{ccccc}
\hline \multirow{2}{*}{ Element } & \multicolumn{3}{c}{ Samples } \\
\cline { 2 - 5 } & $\mathbf{H o}\left(\mathrm{NO}_{3}\right)_{3} \cdot 5 \mathbf{H}_{\mathbf{2}} \mathbf{O}$ & $\boldsymbol{\beta}$-CD & Ho- $\boldsymbol{\beta}$-CD (1:1) & Ho- $\boldsymbol{\beta}$-CD (1:3) \\
\hline $\mathrm{C}$ & $15.40 \pm 4.5$ & $58.66 \pm 1.54$ & $50.86 \pm 10.93$ & $57.11 \pm 4.20$ \\
$\mathrm{O}$ & $67.04 \pm 1.38$ & $41.34 \pm 1.54$ & $47.09 \pm 9.42$ & $41.56 \pm 5.11$ \\
$\mathrm{Ho}$ & $5.45 \pm 3.79$ & & $2.06 \pm 1.89$ & $1.32 \pm 1.03$ \\
$\mathrm{~N}$ & $12.11 \pm 1.40$ & & & \\
\hline
\end{tabular}

\subsection{Absorption Spectra}

Figure 2 shows the absorption spectra for the reagents $\left(\beta\right.$-cyclodextrin and $\left.\mathrm{Ho}\left(\mathrm{NO}_{3}\right)_{3} \cdot 5 \mathrm{H}_{2} \mathrm{O}\right)$ and $\mathrm{Ho}-\beta$-CD inclusion complex. In Figure 2, it was recorded that $\beta$-CD has no absorption in the range $200-700 \mathrm{~nm}$.

Absorption spectra shape for $\left.\mathrm{Ho}\left(\mathrm{NO}_{3}\right)_{3} \cdot 5 \mathrm{H}_{2} \mathrm{O}\right)$ and $\mathrm{Ho}-\beta$-CD inclusion complex were similar, but, the absorbance of Ho- $\beta$-CD inclusion complex was lower than that of $\mathrm{Ho}\left(\mathrm{NO}_{3}\right)_{3} \cdot 5 \mathrm{H}_{2} \mathrm{O}$ alone, due to the formation inclusion complex between $\mathrm{Ho}\left(\mathrm{NO}_{3}\right)_{3} \cdot 5 \mathrm{H}_{2} \mathrm{O}$ and $\beta$-CD. Similar phenomena have been observed by Kavirajaa et al. and Wang et al. [14] [15].

\subsection{Characterization of the Reactants and the Inclusion Compound Ho- $\beta$-CD by Infrared}

Figure 3 shows infrared spectra for the reagents $\left(\beta\right.$-cyclodextrin and $\left.\mathrm{Ho}\left(\mathrm{NO}_{3}\right)_{3} \cdot 5 \mathrm{H}_{2} \mathrm{O}\right)$ and $\mathrm{Ho}-\beta$-CD $(1: 1)$ inclusion complex.

The presence or absences of characteristic peaks associated with specific structural groups of the molecules were noted. The frequencies for pure $\beta$-cyclodextrin observed at $3395.3 \mathrm{~cm}^{-1}, 2924.96 \mathrm{~cm}^{-1}, 1156.52 \mathrm{~cm}^{-1}$, and $1030.16 \mathrm{~cm}^{-1}$ which corresponds to the symmetric and antisymmetric stretching of $\vee[\mathrm{OH}], \vee\left[\mathrm{CH}_{2}\right], \vee[\mathrm{C}-\mathrm{C}]$, and bending vibration of $\mathrm{V}[\mathrm{O}-\mathrm{H}]$ respectively. Meanwhile, IR spectrum of $\mathrm{Ho}\left(\mathrm{NO}_{3}\right)_{3} \cdot 5 \mathrm{H}_{2} \mathrm{O}$ (Figure 3(c)), displays absorption band at $1633 \mathrm{~cm}^{-1}$ ( $\delta \mathrm{OH}$ of $\mathrm{HOH}$ ) and 1482, 1384, 1041.6, 819.6 and $747.87 \mathrm{~cm}^{-1}$ due to the nitrate group [6].

Table 2 and Table 3 have shown the difference in frequencies between $\mathrm{Ho}\left(\mathrm{NO}_{3}\right)_{3} \cdot 5 \mathrm{H}_{2} \mathrm{O}, \beta$-CD and the Ho- $\beta$-CD inclusion complex, respectively. Both tables show some increase in intensity changes, $\Delta \delta$. The increment is due to the insertion of the Ho part into the cavity of $\beta$-CD. The decrease in the frequency between the Ho- $\beta$-CD inclusion complex and its constituent molecule is due to the changes in the microenvironment which 


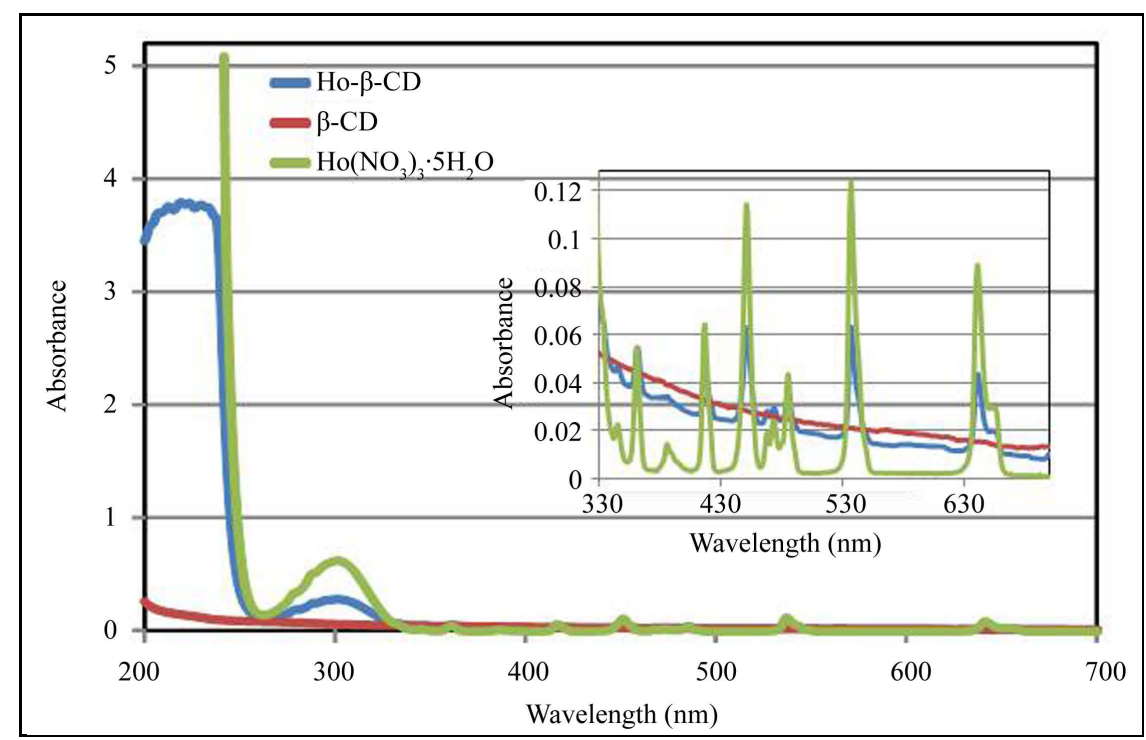

Figure 2. Absorption spectra for the reagents $\left(\beta\right.$-cyclodextrin and $\left.\mathrm{Ho}\left(\mathrm{NO}_{3}\right)_{3} \cdot 5 \mathrm{H}_{2} \mathrm{O}\right)$ and Ho- $\beta$-CD inclusion complex.

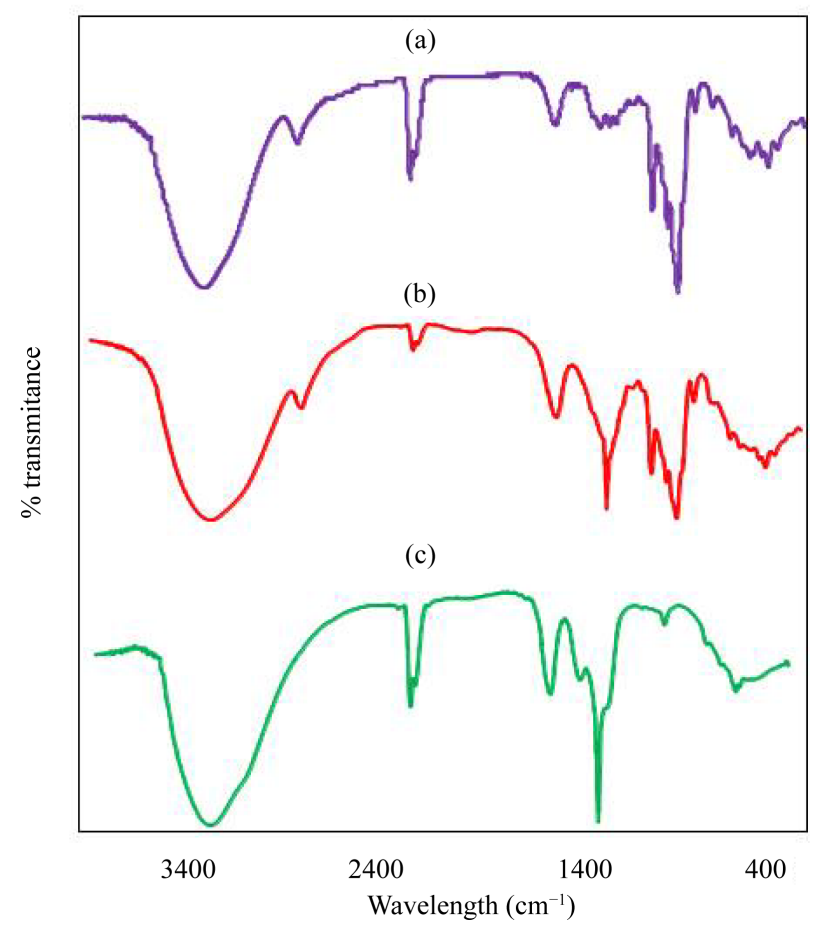

Figure 3. IR spectra in $\mathrm{KBr}$ pellet. (a) $\beta$-CD, (b) Ho- $\beta$-CD, (c) $\mathrm{Ho}\left(\mathrm{NO}_{3}\right)_{3} \cdot 5 \mathrm{H}_{2} \mathrm{O}$.

lead to the formation of hydrogen bonding and the presence of Vander Waals forces during their interaction to form the Ho- $\beta$-CD inclusion complex.

On the other hand, the FTIR spectrum of the Ho- $\beta$-CD inclusion complex imitated the characteristic peak of the $\beta$-CD and the $\mathrm{Ho}\left(\mathrm{NO}_{3}\right)_{3} \cdot 5 \mathrm{H}_{2} \mathrm{O}$, which can be regarded as a simple superimposition of those host and guest molecules. Thus, the FTIR spectra significantly prove the formation of Ho- $\beta$-CD inclusion complex [14].

Furthermore, the absorption bands 1440, 1374, and $1341 \mathrm{~cm}^{-1}$ of the $\beta$-CD disappear (Figure 3(a)), meanwhile the infrared spectrum for $\mathrm{Ho}\left(\mathrm{NO}_{3}\right)_{3} \cdot 5 \mathrm{H}_{2} \mathrm{O}$ show an intense absorption band at $1384.6 \mathrm{~cm}^{-1}$ (Figure $3(\mathrm{c})$ ), 
Table 2. Comparison between the frequencies of $\beta$-CD and the Ho- $\beta$-CD inclusion complex.

\begin{tabular}{cccc}
\hline \multirow{2}{*}{ Functional group } & \multicolumn{3}{c}{ Wavenumber $\left(\mathrm{cm}^{-1}\right)$} \\
\cline { 2 - 4 } & $\beta$-CD & Ho- $\beta$-CD inclusion complex & Changes $\Delta \delta$ \\
\hline$\vee[\mathrm{OH}]$, Symmetric and antisymmetric & 3395.3 & 3393.69 & -1.61 \\
$\vee\left[\mathrm{CH}_{2}\right]$, & 2924.96 & 2928.22 & -3.26 \\
$\vee[\mathrm{C}-\mathrm{C}]$, & 1156.52 & 1156.86 & 0.37 \\
$\vee[\mathrm{O}-\mathrm{H}]$ Bending vibration & 1030.16 & 1029.47 & -0.69 \\
\hline
\end{tabular}

Table 3. Comparison between the frequencies of $\mathrm{Ho}\left(\mathrm{NO}_{3}\right)_{3} \cdot 5 \mathrm{H}_{2} \mathrm{O}$ and the Ho- $\beta$-CD inclusion complex.

\begin{tabular}{cccc}
\hline & & Wavenumber $\left(\mathrm{cm}^{-1}\right)$ & \\
Functional group & $\mathrm{Ho}\left(\mathrm{NO}_{3}\right)_{3} \cdot 5 \mathrm{H}_{2} \mathrm{O}$ & Ho- $\beta$-CD inclusion complex & Changes $\Delta \delta$ \\
\cline { 2 - 4 } & 3398.37 & 3393.69 & -4.68 \\
\hline$[\mathrm{OH}]$, & 1633.04 & 1638.92 & 5.68 \\
$\delta[\mathrm{OH}$ of $\mathrm{HOH}]$ & $1482,1384.65,1041.58,819.61,747.87$ & \\
\hline
\end{tabular}

it is observed in the Ho- $\beta$-CD inclusion complex (at $1387 \mathrm{~cm}^{-1}$ ) (Figure 3(b)), which is an indication of the formation of this inclusion complex.

\subsection{Characterization of the Reactants and the Inclusion Compound Ho- $\beta$-CD by X-Ray Diffraction}

Another method commonly used to study the reagents(Holmium Nitrate Pentahydrate and $\beta$-cyclodextrin) and Holmium- $\beta$-cyclodextrin inclusion complex is XRD. The X ray diffraction spectra of reagents $\left(\mathrm{Ho}\left(\mathrm{NO}_{3}\right)_{3} \cdot 5 \mathrm{H}_{2} \mathrm{O}\right.$ and $\beta$-CD)and Ho- $\beta$-CD inclusion complex are shown in Figure 4. Diffractogram of the Ho- $\beta$-CD inclusion complex and pure compounds differ markedly. $\beta$-CD showed characteristic peaks at $2 \theta$ of $10.9,12.6,15.7,16.9$, 18.9, 19.7, 21.1, 22.8, 24.3, 25.8, 27.2, 28.8, 31.91, and 34.70. In the other hand, X-ray diffraction pattern of $\mathrm{HO}\left(\mathrm{NO}_{3}\right)_{3} \cdot 5 \mathrm{H}_{2} \mathrm{O}$ in its crystalline form exhibits diffraction peaks at $2 \theta$ values of $10.9,11.2,14.2,14.6,15.6$, 16.5, 17.2, 19.4, 22.9, 23.0, 23.8, 24.8, 26.8, 27.2, 28.1, 34.9, 37.9, and 38.9. The XRD pattern of $\mathrm{Ho}\left(\mathrm{NO}_{3}\right)_{3} \cdot 5 \mathrm{H}_{2} \mathrm{O}$ and $\beta$-CD shows intense and sharp peaks that prove the crystalline nature of the compounds (Figure 4(a) and Figure 4(c)). XDR pure standards of a) $\beta$-cyclodextrin, b) $\mathrm{Ho}-\beta$-CD, and c) [ $\mathrm{Ho}\left(\mathrm{NO}_{3}\right)_{3} \cdot 5 \mathrm{H}_{2} \mathrm{O}$ ] [16], which was shown in Figure 4, revealed several diffraction peaks indicating its crystalline nature. Whereas, Ho- $\beta$-CD inclusion complex is characterized by diffraction peaks, which appears in the diffraction angle $2 \theta$ at $10.9,11.99,12.9$, $13.2,14.12,15.4,17.0,17.64,17.97,18.2,19.9,20.9,23.0,23.8$, and 26.1 are differ markedly with the X ray diffraction spectra of reagents [17].

The diffraction pattern of the Ho- $\beta$-CD inclusion complex was found to be different than diffraction pattern of pure $\beta$-CD and $\mathrm{Ho}\left(\mathrm{NO}_{3}\right)_{3} \cdot 5 \mathrm{H}_{2} \mathrm{O}$. Comparing the pattern for Ho- $\beta$-CD inclusion complex with that pure compound marked difference is shown. In complex, the new peaks were found and shift in peak position also where found and have peaks which are superimposition of two individual. The intensity of new peaks confirms complex formation.

\subsection{Characterization of the Reactants and the Inclusion Compound Ho- $\beta$-CD by Raman Spectroscopy}

The insertion of the guest molecule into the cavity of the $\beta$-CD will result in the chemicals shift of guest and host molecule in the Raman spectra. In Figure 5, Raman spectra at positions 1, 2, and 3 are compared with synthetic and reference materials $\left(\beta \mathrm{CD}\right.$, Ho- $\beta \mathrm{CD}$, and $\left.\mathrm{Ho}\left(\mathrm{NO}_{3}\right)_{3} \cdot 5 \mathrm{H}_{2} \mathrm{O}\right)$. The changes in the peak intensities show the gradual decrease/disappear in $\beta \mathrm{CD} / \mathrm{Ho}\left(\mathrm{NO}_{3}\right)_{3} \cdot 5 \mathrm{H}_{2} \mathrm{O}$ amount. The broadening of the Ho- $\beta \mathrm{CD}$ peak, when passing from position 1 and 3 to position 2 across the sample, can be seen. 


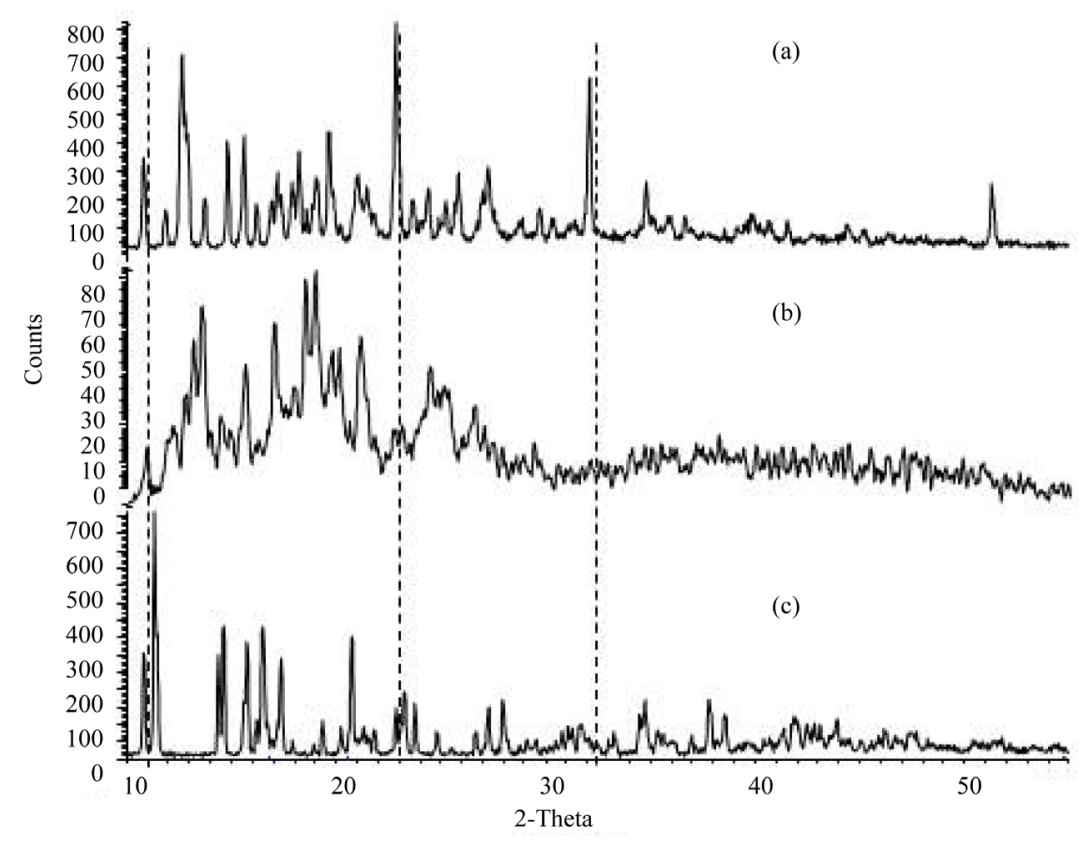

Figure 4. X-ray diffraction analysis of powder samples. (a) $\beta$-CD, (b) Ho- $\beta$-CD, (c) $\mathrm{Ho}\left(\mathrm{NO}_{3}\right)_{3} \cdot 5 \mathrm{H}_{2} \mathrm{O}$.

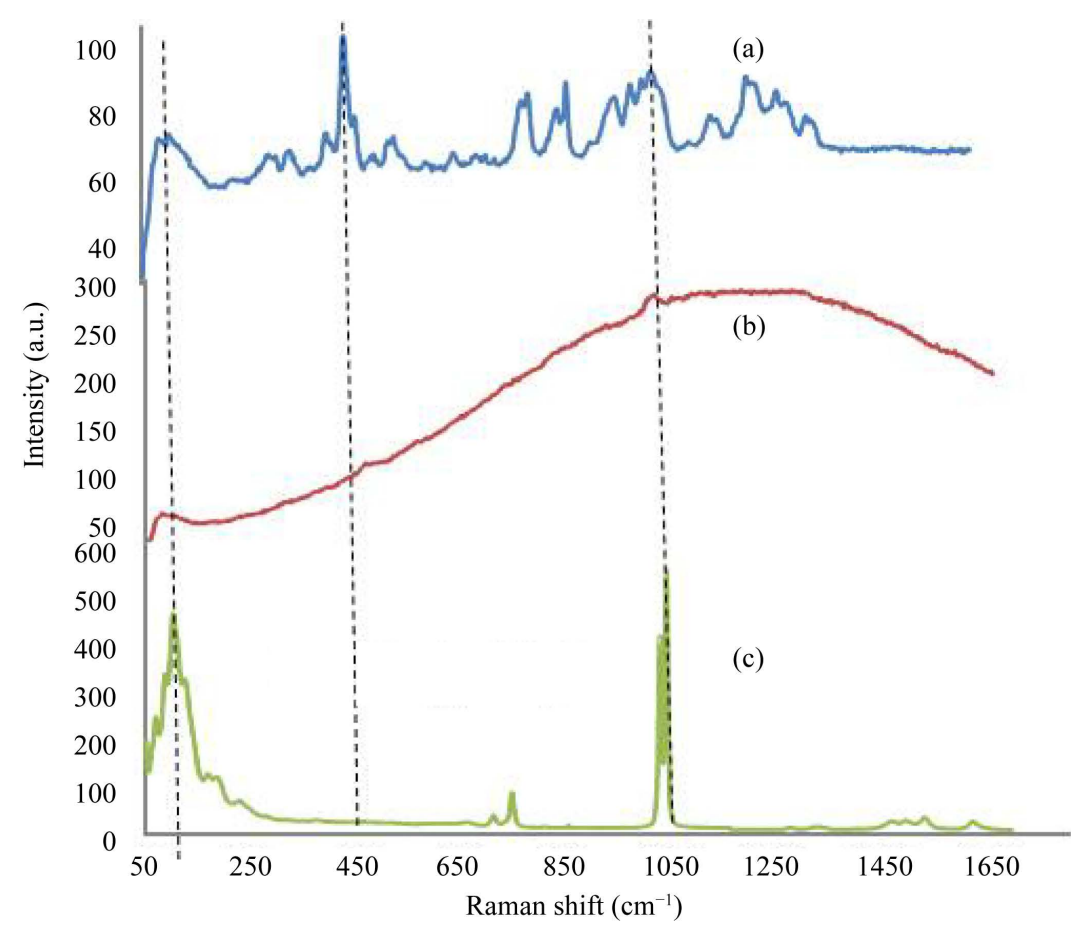

Figure 5. Raman spectra of the $\beta$-cyclodextrin inclusion complex $\beta$-cyclodextrinholmium and holmium nitrate pentahydrate free.

The Raman spectrum obtained in the analysis of the of the $\beta$-cyclodextrin, inclusion complex Ho- $\beta$-CD, and $\mathrm{Ho}\left(\mathrm{NO}_{3}\right)_{3} \cdot 5 \mathrm{H}_{2} \mathrm{O}$ can be observed in Figure 5, in which the Infrared and Raman spectroscopy was performed to ascertain the presence of holmium in the Ho- $\beta$-CD inclusion complex. The Raman spectra of $\left.\mathrm{Ho}\left(\mathrm{NO}_{3}\right)_{3} \cdot 5 \mathrm{H}_{2} \mathrm{O}\right], \beta$ cyclodextrin, Ho- $\beta$-CD (1:1) were virtually different (Figure 5), which implies that the holmium is surrounded by the $\beta$-cyclodextrin. These finding are in agreement with the infrared measurements on Ho- $\beta$-CD inclusion 
complex that showed the same and different peak characteristic as in the reactive.

\section{Conclusion}

The formation of Holmium- $\beta$-cyclodextrin inclusion complex has been achieved. The morphology of the samples is evaluated, which indicates that the chemicals compositions of the inclusion complex formed. FTIR and Raman confirm the presence of Ho in the complex $\beta$-CD, while XRD results suggest that the two components form Holmium- $\beta$-cyclodextrin inclusion complex. This result opens up excellent opportunity to use these materials in internal selective radiotherapy.

\section{References}

[1] Abdelrahman, A.I. (2011) Lanthanide-Encoded Polystyrene Microspheres for Mass Cytometry-Based Bioassays. Thesis, Department of Chemistry, University of Toronto, Toronto.

[2] Zielhuis, S. (2006) Radioactive Particles for Cancer Therapy and Multimodality Imaging. Thesis, University Medical Center Utrecht, Utrecht.

[3] Baran, E.J. (2007) La Nueva Farmacoterapia Inorgánica. XVIII. Compuestos de Lantánidos. Latin American Journal of Pharmacy, 26, 626-634.

[4] Lyra, M., Andreou, M., Georgantzoglou, A., Kardolaimi, S., Lagopati, N., Ploussi, A. and Salvara, A.L. (2011) Ionnis Vamvakas. Nuclear Medicine Therapy. Radiositopes Production and Dosimetry, 2-6.

[5] IAEA-TECDOC-1228 (2011) Herapeutic Applications of Radiopharmaceuticals. Proceedings of an International Seminar, Hyderabad, 18-22 January 1999, 1-6.

[6] Lira, R.A., Myamoto, D.M., Souza, J.R., Nascimento, N., Osso Junior, J.A., Martinelli, J.R. and de Burgos M. de Azevedo, M. (2011) Microspheres with an Ultra-High Holmium Content for Brachytherapy of Malignancies. 2011 International Nuclear Atalntic Conference-INAC 2011, Belo Horizonte, 24-28 October 2011, 12 p.

[7] Yavari, K., Hadi, K., Mohamad, T., Mazidi, M., Bagher, K., Asl, R.S. and Maragheh, M.G. (2013) Development of ${ }^{166}$ Ho Poly Lactic Acid Microspheres for Radiosynovectomy. Journal of Pharamacy and Pharmacolgy, 1, 25-35.

[8] de Lacerda, S.M.V. (2009) Copper, Samarium and Holmium Complexes with Tetraazamacrocycles Potencially Interesting for Nuclear Medicine. Thesis, Departamento de Química e Bioquímica, Faculdad de Ciencias, Universidade de Lisboa, Loures.

[9] Loftsson, T. and Brewster, M.E. (1996) Pharmaceutical Applications of Cycldextrins. 1. Drug Solubilization and Stabilization. Journal of Pharamceutical Science, 85, 1017-1025. http://dx.doi.org/10.1021/js950534b

[10] Moscoso, D.A. (2010) Multifunctional Platforms Based on Cyclodextrins: Design Antitoxins of Anthrax and Gene Vectors. PhD Thesis, Institute of Chemical Research of the Higher Council for Scientific Research, Department of Chemistry, University of Sevilla, Sevilla.

[11] Prakash Rao, B., Sarasija, S., Narendra, C. and Balasangameshwer (2006) Physicochemical Characterization of $\beta$ Cyclodextrin and Hydroxy Ethyl $\beta$-Cyclodextrin Complexes of Rifampicin. ARS Pharmaceutica, 47, 37-59.

[12] Martinez, G. and Gamez, M.A. (2007) Cyclodextrins: Inclusion Complexes with Polymers. Revista Iberoamericana de Polymers, 8, 300-312.

[13] Restrepo, J., Vinasco, L.E., Jaramillo, L.P. and Colmenares, A.J. (2009) Encapsulation of Essential Oils Citral (Cymbopogon citratus) in $\beta$-Cyclodextrins Using Supercritical $\mathrm{CO}_{2}$. Engineering and Competitiveness Magazine, 11, 9-19.

[14] Sambasevam, K.P., Mohamad, S., Sarih, N.M. and Ismail, N.A. (2013) Synthesis and Characterization of the Inclusion Complex of $\beta$-Cyclodextrin and Azomethine. International Journal of Molecular Sciences, 14, 3671-3682. http://dx.doi.org/10.3390/ijms14023671

[15] Wang, H.Y., Han, J. and Xia, G.F. (2007) Spectroscopy Study of Orange G- $\beta$-Cyclodextrin Complex and Its Analytical Application. Spectrochimica Acta Part A: Molecular and Biomolecular, 66, 578-585. http://dx.doi.org/10.1016/j.saa.2006.03.035

[16] Balboul, B.A.A.A. (2000) Physicochemical Characterization of the Decomposition Course of Hydrated Holmium Nitrate. Thermoanalytical Studies. Powder Technology, 107, 168-174. http://dx.doi.org/10.1016/S0032-5910(99)00183-7

[17] Maixner, J. and Bartunek, V. (2012) X-Ray Powder Diffraction Data for Holmium Nitrate Pentahydrate. Powder Diffraction Pattern, 27, 203-207. 